\title{
PEMODELAN KEMISKINAN DI PROVINSI SUMATERA BARAT TAHUN 2018 MENGGUNAKAN REGRESI SPLINE
}

\author{
SITI LATHIFAH IRMA, IZZATI RAHMI HG*'FERRA YANUAR \\ Program Studi S1 Matematika, \\ Fakultas Matematika dan Ilmu Pengetahuan Alam, Universitas Andalas, \\ Kampus UNAND Limau Manis Padang, Indonesia. \\ email : Lathifahirma25@gmail.com,izzatirahmihg@sci.unand.ac.id,ferrayanuar@sci.unand.ac.id
}

Diterima 12 Juni 2021 Direvisi 22 Juni 2021 Dipublikasikan 26 Juli 2021

\begin{abstract}
Abstrak. Kemiskinan dipandang sebagai ketidakmampuan dari sisi ekonomi untuk memenuhi kebutuhan dasar makanan dan bukan makanan yang diukur dari sisi pengeluaran. Penyebab dari kemiskinan sangat berkaitan dengan kepadatan penduduk, perumahan dan pekerjaan. Pemerintah terus berupaya untuk mengatasi permasalahan kemiskinan ini. Agar upaya tersebut tepat, perlu diidentifikasi variabel yang berpengaruh terhadap kemiskinan. Untuk mengetahui variabel yang mempengaruhi kemiskinan dapat digunakan analisis regresi, pendekatan regresi yang digunakan pada penelitian ini adalah regresi spline. Regresi spline yang dipilih adalah yang memiliki titik knot dengan nlai GCV minimum. Hasil pemodelan menunjukkan bahwa dengan regresi spline terbaik adalah regresi spline menggunakan dua titik knot dengan nilai GCV minimum yaitu 0,06 dan $R^{2}$ sebesar 99,97572 persen. Hasil analisis menunjukkan bahwa variabel bebas yang berpengaruh signifikan pada kemiskinan adalah persentase pengeluaran penduduk per kapita, persentase laju pertumbuhan ekonomi, persentase tingkat pengangguran terbuka, rata-rata lama sekolah, dan persentase gizi buruk balita.
\end{abstract}

Kata Kunci: Regresi Spline, Titik Knot, GCV minimum

\section{Pendahuluan}

Kemiskinan merupakan suatu permasalahan sosial yang sangat kompleks yang dipengaruhi oleh beberapa faktor yang saling berkaitan, seperti kualitas sumber daya manusia dan tingkat pendapatan masyarakat. Menurut Badan Pusat Statistik (BPS), pada bulan September 2018 jumlah penduduk miskin di Sumatera Barat mencapai 353,240 ribu orang atau 6,55\% dari seluruh jumlah penduduk Sumatera Barat. Persentase penduduk miskin di daerah perkotaan sebesar 4,99\%, sedangkan persentase penduduk miskin di daerah pedesaan sebesar 7,90\% pada bulan September 2018. Tinggi rendahnya kemiskinan yang terjadi di Provinsi Sumatera Barat 
bergantung dari berbagai faktor, sehingga pemerintah harus memaksimalkan kinerja yang terfokus pada penduduk miskin agar tingkat kemiskinan bisa turun dari sebelumnya [1].

Untuk mengetahui variabel-variabel yang mempengaruhi kemiskinan dapat digunakan analisis regresi. Salah satu pendekatan dalam metode analisis regresi yang digunakan yaitu pendekatan nonparametrik. Terdapat beberapa model regresi nonparametrik, salah satunya adalah model regresi spline. Pola data kemiskinan dan variabel-variabel yang mempengaruhi kemiskinan di Provinsi Sumatera Barat jika dilihat dari scatterplot memiliki pola data yang tidak dapat ditentukan secara pasti bentuknya, sehingga metode analisis yang digunakan pada penelitian ini adalah regresi nonparametrik spline.

\section{Landasan Teori}

\subsection{Regresi Nonparametrik Spline}

Regresi nonparametrik merupakan metode pendekatan regresi yang digunakan ketika tidak terdapat informasi yang lengkap tentang bentuk pola data atau ketika kurva regresi antara variabel bebas dengan variabel terikat tidak diketahui bentuk atau polanya [2]. Penduga estimasi terhadap fungsi $f\left(x_{i}\right)$ dalam regresi nonparametrik dapat dilakukan dengan berbagai pendekatan, salah satunya adalah spline.

Spline merupakan model polinom yang memiliki sifat tersegmen atau terpotongpotong yang terbentuk pada setiap titik knot dan dapat menghasilkan fungsi regresi yang sesuai dengan data, sifat segmen memberikan fleksibelitas yang lebih baik dibanding model polinomial biasa. Spline sangat tergantung pada titik knots. Titik knots merupakan titik perpaduan bersama dimana terjadi pola perubahan perilaku dari suatu fungsi pada selang yang berbeda.

Model regresi nonparametrik spline secara umum sebagai berikut [2].

$$
f\left(x_{i}\right)=\beta_{0}+\sum_{j=1}^{p} \beta_{j} x_{i}^{j}+\sum_{l=1}^{r} \beta_{p+l}\left(x_{i}-K_{l}\right)_{+}^{p}
$$

Fungsi $\left(x_{i}-K_{l}\right)_{+}^{p}$ merupakan fungsi potongan yang didefinisikan sebagai berikut:

$$
\left(x_{i}-K_{l}\right)_{+}^{p}= \begin{cases}\left(x_{i}-K_{l}\right)^{p} & , x_{i} \geq K_{l}, \\ 0 & , x_{i}<K_{l}\end{cases}
$$

dan $K_{1}, K_{2}, \cdots, K_{l}$ adalah titik-titik knot yang memperhatikan pola hubungan perilaku dari fungsi pada sub-sub interval yang berbeda. Nilai $p$ pada persamaan diatas merupakan derajat polinomial.

\subsection{Pemilihan Titik Knot Optimum}

Model spline yang baik adalah model yang mampu menjelaskan hubungan antara variabel bebas $(X)$ dengan variabel terikat $(Y)$ dan memenuhi beberapa kriteria tertentu, yaitu mempunyai nilai Mean Squared Error (MSE) yang minimum dan nilai Generalized Cross Validation (GCV) yang minimum [2]. 
Fungsi GCV didefinisikan sebagai berikut:

$$
G C V\left(K_{1}, K_{2}, \cdots, K_{l}\right)=\frac{1 / n \sum_{i=1}^{n}\left(y_{i}-\hat{f}\left(x_{i}\right)\right)^{2}}{\left(\frac{\operatorname{tr}\left(I-A\left(K_{1}, K_{2}, \cdots, K_{l}\right)\right)}{n}\right)^{2}}
$$

dimana $\operatorname{MSE}\left(K_{1}, K_{2}, \cdots, K_{l}\right)=\frac{1}{n} \sum_{i=1}^{n}\left(y_{i}-\hat{f}\left(x_{i}\right)\right)^{2} . K_{1}, K_{2}, \cdots, K_{l}$ adalah titik knot dan matriks $A\left(K_{1}, K_{2}, \cdots, K_{l}\right)$ diperoleh dari persamaan [3] $\boldsymbol{Y}=\boldsymbol{A} \boldsymbol{Y}+\varepsilon$ $A=X\left(X^{T} X\right)^{-1} X^{T}$

\section{Pembahasan}

\subsection{Pemilihan Titik Knot dengan Satu Titik Knot}

Estimasi model regresi nonparametrik spline dengan satu titik knot sebagai berikut:

$$
\begin{aligned}
\hat{y}= & \beta_{0}+\beta_{1} x_{1}+\beta_{2}\left(x_{1}-K_{1}\right)_{+}^{1}+\beta_{3} x_{2}+\beta_{4}\left(x_{2}-K_{2}\right)_{+}^{1}+\beta_{5} x_{3}+\beta_{6}\left(x_{3}-K_{3}\right)_{+}^{1}+ \\
& \beta_{7} x_{4}+\beta_{8}\left(x_{4}-K_{4}\right)_{+}^{1}+\beta_{7} x_{5}+\beta_{8}\left(x_{5}-K_{5}\right)_{+}^{1}
\end{aligned}
$$

Nilai GCV untuk model satu titik knot disajikan pada Tabel 1

Tabel 1. Nilai GCV dengan Satu Titik Knot

\begin{tabular}{|c|c|c|c|c|c|}
\hline \multirow{2}{*}{ GCV } & \multicolumn{5}{|c|}{ Knot } \\
\cline { 2 - 6 } & $X_{1}$ & $X_{2}$ & $X_{3}$ & $X_{4}$ & $X_{5}$ \\
\hline 2.70 & 13.11 & 4.94 & 2.45 & 7.07 & 11.99 \\
\hline 2.70 & 13.64 & 4.97 & 2.62 & 7.18 & 12.42 \\
\hline 2.54 & 24.82 & 5.61 & 6.35 & 9.60 & 21.31 \\
\hline 2.29 & 25.36 & 5.64 & 6.52 & 9.71 & 21.73 \\
\hline 2.12 & 25.89 & 5.67 & 6.70 & 9.83 & 22.15 \\
\hline $\mathbf{2 . 0 2}$ & $\mathbf{2 6 . 4 2}$ & $\mathbf{5 . 7 0}$ & $\mathbf{6 . 8 8}$ & $\mathbf{9 . 9 4}$ & $\mathbf{2 2 . 5 8}$ \\
\hline 2.31 & 26.95 & 5.73 & 7.05 & 10.06 & 23.00 \\
\hline 2.66 & 27.48 & 5.76 & 7.23 & 10.17 & 23.42 \\
\hline 2.67 & 32.28 & 6.03 & 8.83 & 11.21 & 27.23 \\
\hline 2.55 & 32.81 & 6.06 & 9.00 & 11.32 & 27.66 \\
\hline
\end{tabular}

Berdasarkan Tabel 1 didapatkan nilai GCV minimum sebesar 2,02 yang bersesuaian dengan knot $K_{1}=26,42 ; K_{2}=5,70 ; K_{3}=6,88 ; K_{4}=9,94 ; K_{5}=22,58$.

\subsection{Pemilihan Titik Knot dengan Dua Titik Knot}

Berikut adalah model regresi nonparametrik spline untuk dua titik knot.

$\hat{y}=\beta_{0}+\beta_{1} x_{1}+\beta_{2}\left(x_{1}-K_{1}\right)_{+}^{1}+\beta_{3}\left(x_{1}-K_{2}\right)_{+}^{1}+\beta_{4} x_{2}+\beta_{5}\left(x_{2}-K_{3}\right)_{+}^{1}+$ $\beta_{6}\left(x_{2}-K_{4}\right)_{+}^{1}+\beta_{7} x_{3}+\beta_{8}\left(x_{3}-K_{5}\right)_{+}^{1}+\beta_{9}\left(x_{3}-K_{6}\right)_{+}^{1}+\beta_{10} x_{4}+$ 


$$
\beta_{11}\left(x_{4}-K_{7}\right)_{+}^{1}+\beta_{12}\left(x_{4}-K_{8}\right)_{+}^{1}+\beta_{13} x_{5}+\beta_{14}\left(x_{5}-K_{9}\right)_{+}^{1}+\beta_{15}\left(x_{5}-K_{10}\right)_{+}^{1}
$$

Nilai GCV untuk model dua titik knot disajikan pada Tabel 2.

Tabel 2. Nilai GCV dengan Dua Titik Knot

\begin{tabular}{|c|c|c|c|c|c|}
\hline \multirow{2}{*}{ GCV } & \multicolumn{5}{|c|}{ Knot } \\
\cline { 2 - 6 } & $X_{1}$ & $X_{2}$ & $X_{3}$ & $X_{4}$ & $X_{5}$ \\
\hline 0.20 & 18.44 & 5.24 & 4.22 & 8.22 & 16.23 \\
\cline { 2 - 6 } & 24.82 & 5.61 & 6.35 & 9.60 & 21.31 \\
\hline 0.37 & 18.97 & 5.27 & 4.40 & 8.33 & 16.65 \\
\cline { 2 - 6 } & 23.23 & 5.52 & 5.81 & 9.25 & 20.04 \\
\hline 0.11 & 18.97 & 5.27 & 4.40 & 8.33 & 16.65 \\
\cline { 2 - 6 } & 24.29 & 5.58 & 6.17 & 9.48 & 20.88 \\
\hline 0.26 & 18.97 & 5.27 & 4.40 & 8.33 & 16.65 \\
\cline { 2 - 6 } & 24.82 & 5.61 & 6.35 & 9.60 & 21.31 \\
\hline 0.13 & 20.03 & 5.33 & 4.75 & 8.56 & 17.50 \\
\cline { 2 - 6 } & 22.16 & 5.45 & 5.46 & 9.02 & 19.19 \\
\hline $\mathbf{0 . 0 6}$ & $\mathbf{1 9 . 5 0}$ & $\mathbf{5 . 3 0}$ & $\mathbf{4 . 5 7}$ & $\mathbf{8 . 4 5}$ & $\mathbf{1 7 . 0 7}$ \\
\cline { 2 - 6 } & $\mathbf{2 3 . 2 3}$ & $\mathbf{5 . 5 2}$ & $\mathbf{5 . 8 1}$ & $\mathbf{9 . 2 5}$ & $\mathbf{2 0 . 0 4}$ \\
\hline 0.28 & 20.03 & 5.33 & 4.75 & 8.56 & 17.50 \\
\cline { 2 - 6 } & 23.76 & 5.55 & 5.99 & 9.37 & 20.46 \\
\hline 0.34 & 20.56 & 5.36 & 4.93 & 8.68 & 17.92 \\
\cline { 2 - 6 } & 21.10 & 5.39 & 5.10 & 8.79 & 18.34 \\
\hline 0.36 & 20.56 & 5.36 & 4.93 & 8.68 & 17.92 \\
\cline { 2 - 6 } & 23.76 & 5.55 & 5.99 & 9.37 & 20.46 \\
\hline 0.23 & 20.56 & 5.36 & 4.93 & 8.68 & 17.92 \\
\cline { 2 - 6 } & 24.29 & 5.58 & 6.17 & 9.48 & 20.88 \\
\hline
\end{tabular}

Pada Tabel 2 didapatkan informasi bahwa nilai GCV minimum yang didapatkan sebesar 0,06 yang bersesuaian dengan titik-titik knot $K_{1}=19,50 ; K_{2}=23,23$; $K_{3}=5,30 ; \quad K_{4}=5,52 ; \quad K_{5}=4,57 ; \quad K_{6}=5,81 ; \quad K_{7}=8,45 ; \quad K_{8}=9,25 ; \quad K_{9}=17,07 ; \quad$ dan $K_{10}=20,04$.

\subsection{Pemilihan Titik Knot Optimum}

Berdasarkan uji pemilihan titik knot untuk satu knot dan dua knot, didapatkan bahwa nilai GCV dengan dua titik knot bernilai lebih kecil dari nilai GCV satu titik knot sehingga model dengan dua titik knot lebih baik daripada dengan satu titik knot.

Nilai GCV minimum yang diperoleh dengan menggunakan satu knot dan dua knot ditunjukkan oleh Tabel 3.

Titik knot yang optimum merupakan titik knot yang menghasilkan nilai GCV paling minimum, pada Tabel 3 terlihat bahwa nilai GCV yang minimum yaitu sebesar 0,06 sehingga model regresi nonparametrik spline adalah sebagai berikut. 
Tabel 3. Pemilihan Titik Knot Optimum

\begin{tabular}{|c|c|}
\hline Model Regresi Spline & Nilai GCV \\
\hline 1 knot & 2.02 \\
\hline $\mathbf{2}$ knot & $\mathbf{0 . 0 6}$ \\
\hline
\end{tabular}

$$
\begin{aligned}
\hat{y}= & -13,29+0,74 x_{1}-1,71\left(x_{1}-19,50\right)_{+}^{1}+1,07\left(x_{1}-23,23\right)_{+}^{1}+2,45 x_{2} \\
& -10,66\left(x_{2}-5,30\right)_{+}^{1}+12,80\left(x_{2}-5,52\right)_{+}^{1}+0,66 x_{3}-0,32\left(x_{3}-4,57\right)_{+}^{1} \\
& -1,15\left(x_{3}-5,81\right)_{+}^{1}-2,31 x_{4}-3,01\left(x_{4}-8,45\right)_{+}^{1}+7,24\left(x_{4}-9,25\right)_{+}^{1} \\
& +0,85 x_{5}-2,07\left(x_{5}-17,07\right)_{+}^{1}+1,96\left(x_{5}-20,04\right)_{+}^{1}
\end{aligned}
$$

Berdasarkan model diatas didapatkan nilai koefisien determinasi atau $R^{2}$ yang diperoleh sebesar $99.97572 \%$. Berdasarkan kriteria nilai koefisien determinasi, model yang baik adalah model dengan nilai koefisien determinasi mendekati 1 . Dengan demikian dapat dikatakan bahwa model regresi nonparametrik spline yang dihasilkan merupakan model yang baik dan layak digunakan untuk pemodelan.

\section{Kesimpulan}

Berdasarkan hasil pengolahan data yang sudah dibahas pada bab pembahasan diperoleh model kemiskinan di Provinsi Sumatera Barat tahun 2018 sebagai berikut.

$$
\begin{aligned}
\hat{y}= & -13,29+0,74 x_{1}-1,71\left(x_{1}-19,50\right)_{+}^{1}+1,07\left(x_{1}-23,23\right)_{+}^{1}+2,45 x_{2} \\
& -10,66\left(x_{2}-5,30\right)_{+}^{1}+12,80\left(x_{2}-5,52\right)_{+}^{1}+0,66 x_{3}-0,32\left(x_{3}-4,57\right)_{+}^{1} \\
& -1,15\left(x_{3}-5,81\right)_{+}^{1}-2,31 x_{4}-3,01\left(x_{4}-8,45\right)_{+}^{1}+7,24\left(x_{4}-9,25\right)_{+}^{1} \\
& +0,85 x_{5}-2,07\left(x_{5}-17,07\right)_{+}^{1}+1,96\left(x_{5}-20,04\right)_{+}^{1}
\end{aligned}
$$

Berdasarkan model kemiskinan diatas, ini menunjukkan bahwa semua variabel bebas memiliki pengaruh yang signifikan terhadap kemiskinan di Provinsi Sumatera Barat tahun 2018. Variabel bebas yang mempengaruhi kemiskinan di Provinsi Sumatera Barat tahun 2018 yaitu persentase pengeluaran penduduk perkapita $\left(X_{1}\right)$, persentase laju pertumbuhan ekonomi $\left(X_{2}\right)$, persentase tingkat pengangguran terbuka $\left(X_{3}\right)$, rata-rata lama sekolah $\left(X_{4}\right)$ dan persentase gizi buruk balita $\left(X_{5}\right)$.

\section{Ucapan Terima kasih}

Terimakasih kepada Bapak Dodi Devianto, Bapak Ahmad Iqbal Baqi dan Ibu Nova Noliza Bakar yang telah memberikan masukan dan saran, sehingga penelitian ini dapat diselesaikan dengan baik.

\section{Daftar Pustaka}

[1] Badan Pusat Statistik. (2018). Data dan Informasi Kemiskinan. Jakarta: Badan Pusat Statistik.

[2] Eubank, R. L. (1999). Spline Smoothing and Nonparametric Regression Second Edition. New York: Marcel Dekker.

[3] Montgomery, D. C., Peck, E. A., \& Vining, G. G. (2012). Introduction To Linier Regression Analysis fifth Edition. New Jersey: John Wiley \& Sons, Inc. 